\title{
Surgical management of chronic lateral ankle instability: a meta-analysis
}

Yongxing $\mathrm{Cao}^{1}$, Yuan Hong ${ }^{1}$, Yang $\mathrm{Xu}^{1}$, Yuan $\mathrm{Zhu}^{2}$ and Xiangyang $\mathrm{Xu}^{1,2^{*}}$

\begin{abstract}
Background: A key point to surgical treatment of chronic lateral ankle instability is choosing a suitable surgical procedure. The purpose of this meta-analysis was to compare different surgical techniques for management of chronic lateral ankle instability.

Methods: We searched the Cochrane Library, MEDLINE, and EMBASE. All identified randomized and quasi-randomized controlled trials of operative treatment for chronic lateral ankle instability were included. Two review authors independently extracted data from each study and assessed risk of bias. Where appropriate, results of comparable studies were pooled.
\end{abstract}

Results: Seven randomized controlled trials were included for analysis. They fell in five clearly distinct groups. One study comparing two different kinds of non-anatomic reconstruction procedures (dynamic and static tenodesis) found two clinical outcomes favoring static tenodesis: better clinical satisfaction and fewer subsequent sprains. Two studies compared non-anatomic reconstruction versus anatomic repairment. In one study, nerve damage was more frequent in non-anatomic reconstruction group; the other one reported that radiological measurement of ankle laxity showed that non-anatomic reconstruction provided higher reduction of talar tilt angle.

Two studies comparing two anatomic repairment surgical techniques (transosseous suture versus imbrication) showed no significant difference in any clinical outcome at the follow-up except operation time.

One study compared two different anatomic repairment techniques. They found that the double anchor technique was superior with respect to the reduction of talar tilt than single anchor technique.

One study compared an anatomic reconstruction procedure with a modified Brostrom technique. Primary reconstruction combined with ligament advanced reinforcement system results in better patient-scored clinical outcome, at 2 years post-surgery, than the modified Brostrom procedure.

Conclusions: There is limited evidence to support any one surgical technique over another surgical technique for chronic lateral ankle instability, but based on the evidence, we could still get some conclusions: (1) There are limitations to the use of dynamic tenodesis, which obtained poor clinical satisfaction and more subsequent sprains. (2) Non-anatomic reconstruction abnormally increased inversion stiffness at the subtalar level as compare with anatomic repairment. (3) Multiple types of modified Brostrom procedures could acquire good clinical results. (4) Anatomic reconstruction is a better procedure for some specific patients.

Keywords: Ankle sprain, Ankle instability, Lateral ligament injury, Surgical treatment, Meta-analysis

\footnotetext{
* Correspondence: star2110599@163.com

'Department of Orthopedics, Ruijin Hospital North, Shanghai Jiao Tong

University School of Medicine, Shanghai, China

${ }^{2}$ Department of Orthopedics, Ruijin Hospital, Shanghai Jiao Tong University

School of Medicine, Shanghai, China
}

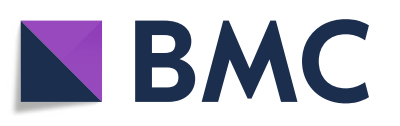

(c) The Author(s). 2018 Open Access This article is distributed under the terms of the Creative Commons Attribution 4.0 International License (http://creativecommons.org/licenses/by/4.0/), which permits unrestricted use, distribution, and reproduction in any medium, provided you give appropriate credit to the original author(s) and the source, provide a link to the Creative Commons license, and indicate if changes were made. The Creative Commons Public Domain Dedication waiver (http://creativecommons.org/publicdomain/zero/1.0/) applies to the data made available in this article, unless otherwise stated. 


\section{Background}

Acute lateral ankle ligament injury is one of the most common problems in foot and ankle medicine [1]. The lateral ankle ligament complex consists of the anterior talofibular ligament (ATFL), the calcaneofibular ligament (CFL), and the posterior talofibular ligament (PTFL). The weakest of the three lateral ankle ligaments is the ATFL, which is the most frequently injured in ankle sprains, whereas the CFL is involved in $50 \sim 75 \%$ of such injuries, and the PTFL in $<10 \%$ [2]. The ATFL rupture is evaluated by the anterior drawer test, which is generally classified as mild, moderate, and severe degree. The CFL is rarely injured alone, but is associated with ATFL tears in more severe injuries. The CFL rupture is evaluated by the talar tilt test and is corroborated with a stressed anteroposterior radiograph. The PTFL is the strongest ligament of the lateral ligament complex and is rarely injured [3]. After injury, initial treatment is usually conservative, such as functional rehabilitation. An incidence of $10-30 \%$ of patients will fail conservative treatment, result in chronic ankle instability (CAI), and require surgical management [4].

To date, many surgical procedures have been described to manage chronic ankle instability, indicating the complexity of the current status. These procedures and their modifications fall into the following three categories: non-anatomic reconstruction, anatomic repairment, and anatomic reconstruction [1].

Non-anatomic reconstruction procedures use various configurations of local tendon grafts to accomplish the restriction function of the ligament without repair of the ligament remnants. Several techniques have been described, including partial or complete tenodesis from the Achilles tendon or peroneal tendon [5] or allografts mimicking the function of the lateral ankle ligaments such as the Chrisman-Snook (CS) procedure, the Watson-Jones procedure, and the modified Evans procedure [6-8].

Anatomic repairment is to restore normal anatomy and joint mechanics by in situ repair of the injured ligament. Anatomic repairment includes repair ligaments by either shortening and fixing them to the bone surfaces or augmenting them with local structures to enhance the repairment. A typical example is the Brostrom-Gould procedure [9], which enhances the original ligaments with the extensor retinaculum and has proved to be a strong procedure without sacrificing other normal structures [5].

Anatomic reconstruction procedures use tendon grafts to recreate joint biomechanics anatomically by replicating the anatomic positions of the ATFL and CFL origin and insertion sites. They vary in the means by which they attain that positioning, including the number and angle of tunnels in the fibula and the fixation techniques selected in each bone tunnel location [1, 10-13].

A key point to surgical treatment of chronic lateral ankle instability is choosing a suitable surgical procedure, which is a complex question that has many arguments in the theory and clinical practice. The biggest limiting factor is that there are few high-quality controlled trials available to assist foot and ankle surgeons in making an informed decision.

The purpose of this meta-analysis was to perform an extensive review of the literature systematically and to attempt to compare different surgical techniques for management of chronic lateral ankle instability.

\section{Methods}

This meta-analysis was reported according to the preferred reporting items for systematic reviews and meta-analysis guidelines. All analyses were based on previous published studies; thus, no ethical approval and patient consent are required.

\section{Criteria for considering studies for this review Eligible trial design}

Any randomized and quasi-randomized (methods of allocating participants to a treatment which is not strictly random, e.g., by date of birth, hospital record number, alternation) controlled clinical trial evaluating any surgical treatments for chronic lateral ankle instability in adults was considered for inclusion. Chronic lateral ankle instability was defined as symptoms of lateral ankle instability, giving way or recurrent sprains, persisting for more than 6 months.

\section{Patient characteristics}

Studies including adult participants with chronic lateral ankle instability who underwent a surgical intervention were included. Trials containing adults and children were included if separate data for adults could be obtained. Studies evaluating exclusively with people with congenital deformities or children or degenerative conditions were excluded. Studies dealing exclusively with the prevention of ankle sprains in healthy individuals or conservative intervention of acute injury to the lateral ankle ligaments were also excluded.

\section{Intervention-comparator characteristics}

Trials comparing different types of surgical treatment used for treating chronic lateral ankle instability were included. We planned to include all three major types of surgical interventions (non-anatomic reconstruction, anatomic repairment, and anatomic reconstruction) and compare the clinical effect of 
different operative approaches. In this article, we define anatomic repairment as the primary or secondary suturing of the torn lateral ligaments at their anatomic position. The Brostrom procedure is a true repairment of the lateral ligaments. The classic Brostrom procedure is rarely performed as an operative technique alone. It is usually augmented with the mobilized lateral portion of the extensor retinaculum or periosteal flap. This kind of procedure is considered as a modified Brostrom procedure (MB). The procedure may be performed in the traditional manner through drill holes or with bone anchors [9, 14-16]. We define reconstruction as the replacement of the chronically deficient lateral ligaments with local tissues or with autograft or allograft tissue. Anatomic reconstruction is placement of the transferred tendon grafts in such a way as to replicate the anatomic positions of the ATFL and CFL origin sites. These procedures vary in the means of the fixation techniques selected in each bone tunnel location. The position, number, and angle of tunnels are varied, too. Non-anatomic reconstruction stabilizes the ankle using tendon grafts placed non-anatomically, such as the CS, Evans, and Watson-Jones procedure. In reconstruction procedures, there are many different ways the ligament graft can be secured in the bone including anchors, bone tunnels with interference screws, and endobutton-type devices [10-13].

\section{Clinical state}

\section{Subjective evaluation of symptoms}

(1) Satisfaction after operation: For the assessment of clinical outcomes post-operation, the Karlsson score and/or FAOS (foot and ankle outcome score) and/or the Sefton grading system were used. The Karlsson score and FAOS are methods of evaluating improvement in postoperative function and outcome by examining the stability of the ankle joint, pain, swelling, range of motion, activities at work or during sports, activities of daily living, the ability to climb stairs, running ability, and the use of ankle support aids. The Sefton grade was measured postoperatively at the follow-up visit and was classified as excellent, good, fair, or poor. Grades greater than good were considered as satisfactory treatment results.

(2) Subjective instability, pain, and swelling: Some studies did not use the grading system to assess the functional outcomes, but instead provide the number of patients with subjective instability, pain, swelling, and so on.

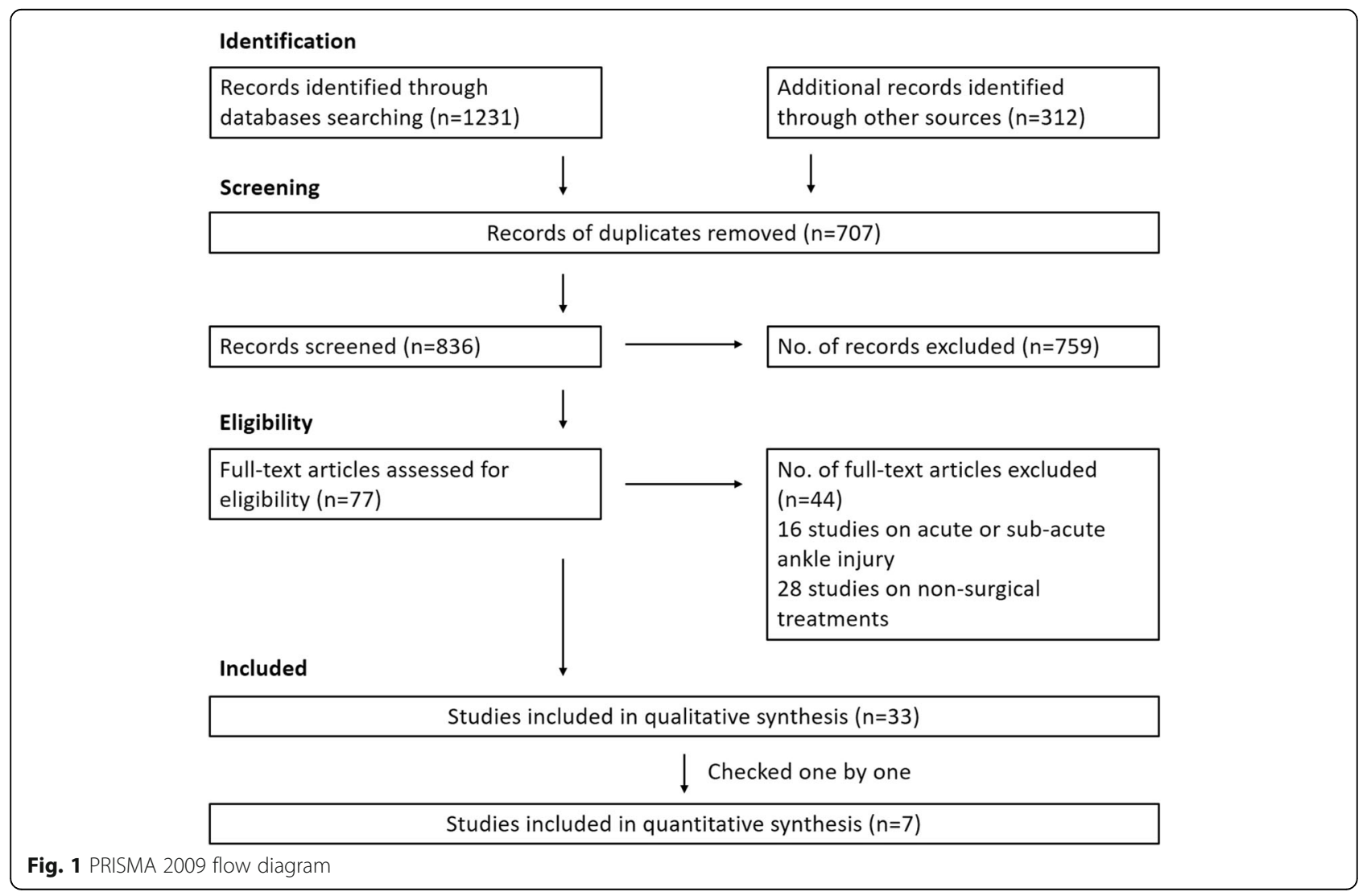


Clinical measurements For clinical assessment, the anterior drawer and varus stress radiography were measured preoperatively and at the follow-up visit in most studies. We collected preoperative and postoperative data of anterior talar translation and the talar tilt angle for comparison.

Complications We collected data for intraoperative complications (drill hole fracture, breakage of the anchor, etc.) and postoperative ones (wound complications, nerve damage, stiffness, subsequent sprains, deep vein thrombosis, revision, etc.)

\section{Search methods for identification of studies}

We searched the Cochrane Library (to December 2016), MEDLINE (1990 to December 2016), and EMBASE (1990 to December 2016). We did not apply any language restrictions. In MEDLINE (PubMed online), a subject-specific strategy was combined with the Cochrane Highly Sensitive Search Strategy for identifying randomized trials. Search strategies for Cochrane, MEDLINE, and EMBASE can be found in Additional file 1. We looked for reference lists of articles deemed eligible in the field to identify further studies or additional data. We also attempted to locate unpublished material or contact researchers for unpublished studies.

\section{Data collection}

The titles and abstracts of all downloaded documents from the electronic searches were screened by CYX, who discarded clearly irrelevant reports. The remaining citations were then screened independently by CYX and $\mathrm{HY}$ to establish the need for obtaining full-text articles. Full-text articles were also obtained where there was any uncertainty about the relevance of the study. Subsequently, CYX and HY independently selected studies according to the inclusion criteria of the review. Disagreements were resolved by consultation and discussion with another review author (ZY).

Two review authors (CYX and HY) independently extracted data from each trial using a data extraction form and entered data into Review Manager 5.3 [17]. We recorded qualitative details and data regarding the study groups, interventions, and outcomes. Where necessary, we contacted trial authors for further details. Any differences in the data extraction between the review authors were resolved by discussion with a third review author (ZY).

\section{Evaluation of trial quality}

Two review authors (CYX and HY) independently assessed the risk of bias in the included studies. Any differences were resolved by a consensus procedure, followed, if required, by scrutiny from a third review author (ZY). We used The Cochrane Collaboration's "Risk of bias tool" [18]. Each study was graded for risk of bias in each of the following domains: adequate sequence generation, allocation concealment, blinding, incomplete outcome data addressed, free of selective outcome reporting, and free of other bias. Due to the nature of the interventions, assessors blinding was evaluated too.

\section{Data analysis}

Treatment effect was measured using risk ratios and 95\% confidence intervals for dichotomous data. Mean differences (MD), standardized mean differences (SMD), and 95\% confidence intervals were calculated for continuous outcomes. When the measurement method or unit of the same intervention effect is exactly the same, MD was chosen. When different measurement methods or units are used for the same intervention effect, SMD was chosen.

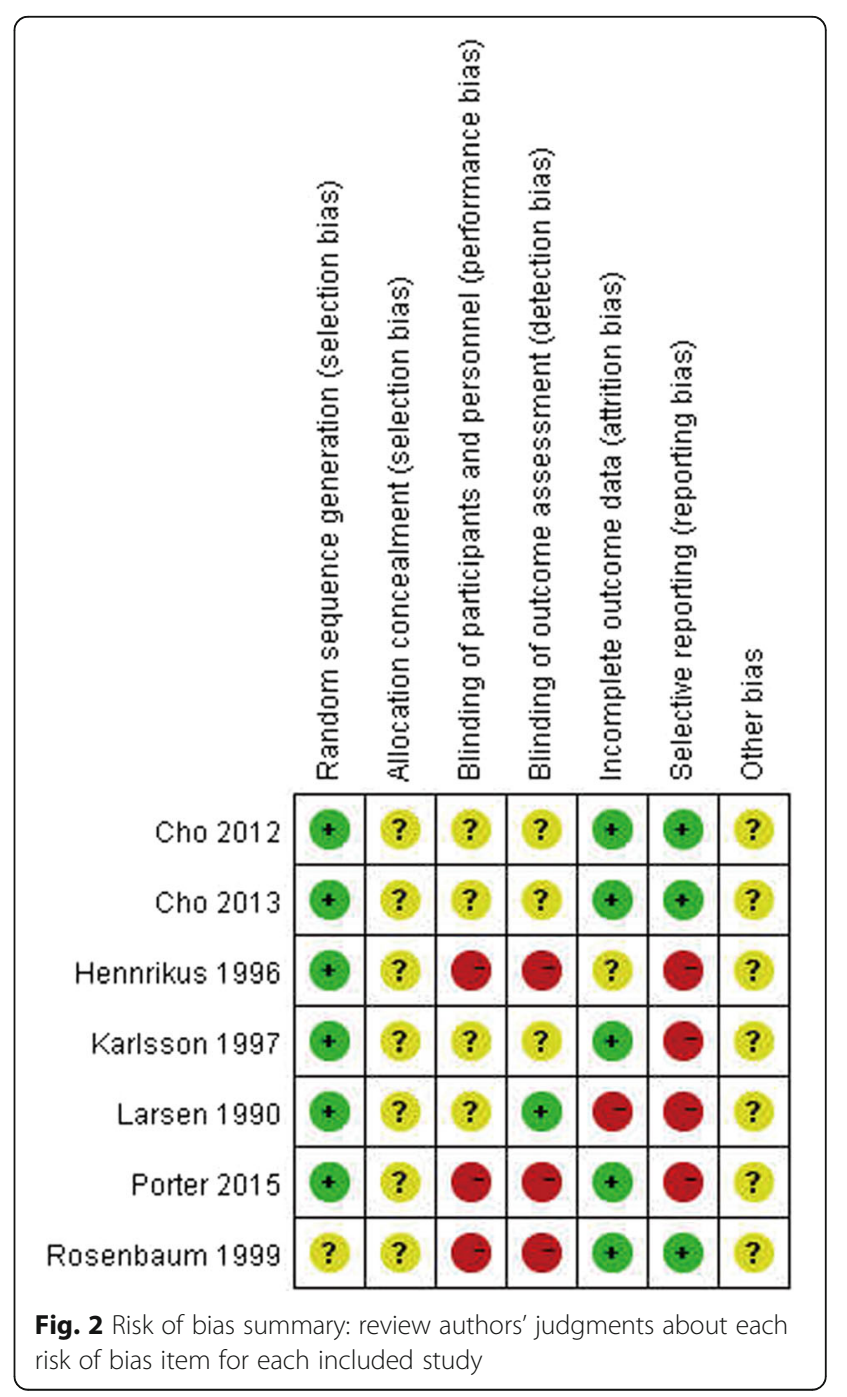


Trail investigators were contacted for missing data if necessary. No studies with missing information on the variance measure were found. Where appropriate, we performed intention-to-treat analyses and were alert to the possibility of unreported loss to follow-up.

We combined trial results only where the participant groups, interventions, and outcome measures were sufficiently similar, as judged by clinical criteria and consideration of the statistical heterogeneity. Between-study variance was estimated using the DerSimonian and Laired estimator.

The data available from the included trials were insufficient to carry out our preplanned subgroup analyses (isolated ATFL repair versus ATFL and CFL repair; open versus mini-invasive approach) as well as a set of sensitivity analyses to examine the impact of the inclusion of trials with a high risk of bias, and also the effects of missing data on trial results.

\section{Results}

\section{Description of studies}

We identified and screened a total 1231 records from the following databases: Cochrane Library (327), MEDLINE (593), and EMBASE (311). Another 312 articles were identified through screening the reference list of included studies. After removing duplicates, 836 titles and abstracts were reviewed. We identified no relevant trials from searching conference proceedings or the reference lists of the included studies. A total of 77 potentially trials were identified. We excluded a total of 16 studies on acute or sub-acute ankle injury [19-34] and 28 studies on non-surgical treatments [35-62]. The remaining 33 studies were eligible for further analysis (Fig. 1).

Seven studies were included for analysis [63-69]. All studies were published in English between 1990 and 2016 and identified in the Cochrane Library, MEDLINE, or EMBASE. All studies evaluated patients with CAI. They are summarized below, with a full summary for each trial detailed in the characteristics of included studies (Additional files 2, 3, 4, 5, 6, 7, and 8).

As expected, the unit of randomization was the individual patient in the included studies. There were no trials with a cluster-randomized design. None of the seven studies evaluated exactly the same criteria. Larsen [67] compared a dynamic tenodesis with a static tenodesis. Both procedures were non-anatomic reconstruction. The main outcome measures were a self-designed evaluation scheme and postoperative complications. Two studies compared an anatomic repairment with non-anatomic reconstruction [65, 69]. Hennrikus et al. [65] compared the outcome after a $\mathrm{MB}$ procedure with the CS procedure in 42 ankles. The main outcome measure was the Sefton ankle score, radiographic stability, and postoperative complications. Rosenbaum et al. [69] compared the outcome after a MB procedure with the Evans procedure in 20 participants. The main outcome measures were manual evaluation of joint mobility and radiographic stability. The other two studies compared a transosseous anatomic repairment procedure with an imbrication procedure [63, 66]. Cho et al. [63] compared a MB procedure with a transosseous suture procedure. The main outcome measure was Karlsson score, radiographic stability, and complications. Karlsson et al. [66] compared two different anatomic repairment in 60 patients. The lateral ankle ligaments were shortened by transosseous suture in one group. In the other group, the lateral ligaments were imbricated and reinforced by the inferior extensor retinaculum, a $\mathrm{MB}$ procedure. The main outcome measure was the Karlsson score, radiographic stability, and postoperative complications. Cho et al. [64] compared single anchor $\mathrm{MB}$ procedure with double anchor MB procedure in 50 patients. The main outcome measures were Karlsson score, radiographic stability, and complications. Porter et al. [68] compared a MB procedure with an anatomic reconstruction procedure with

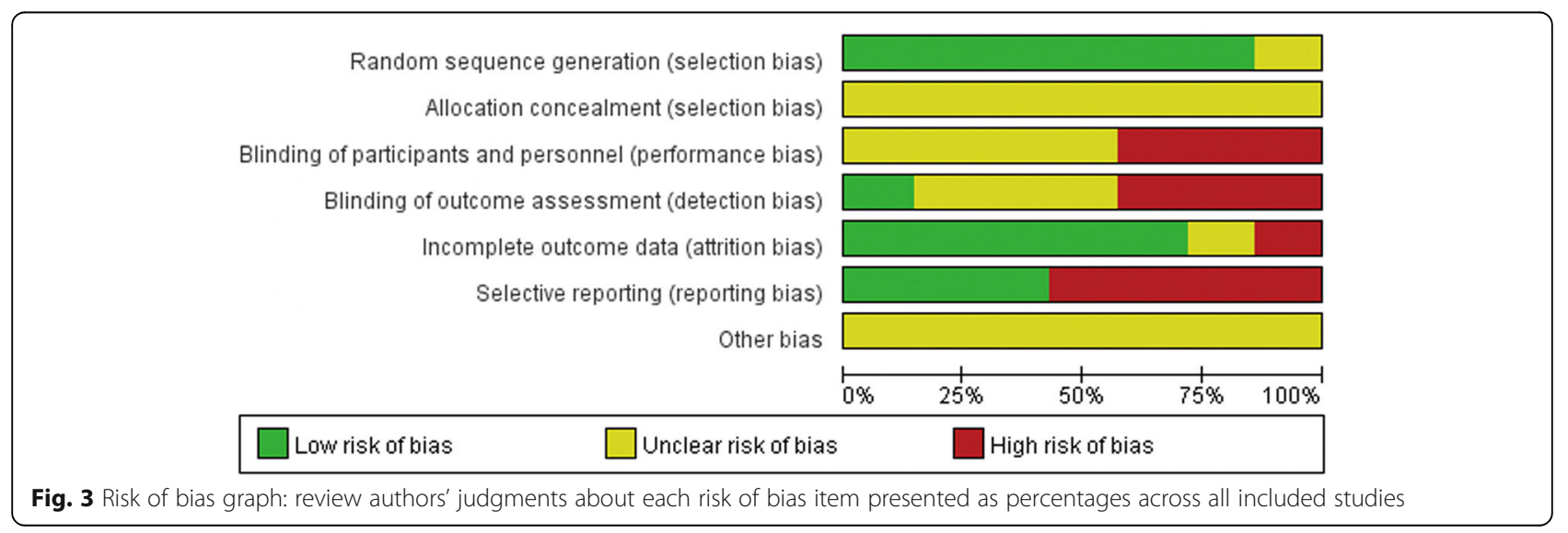




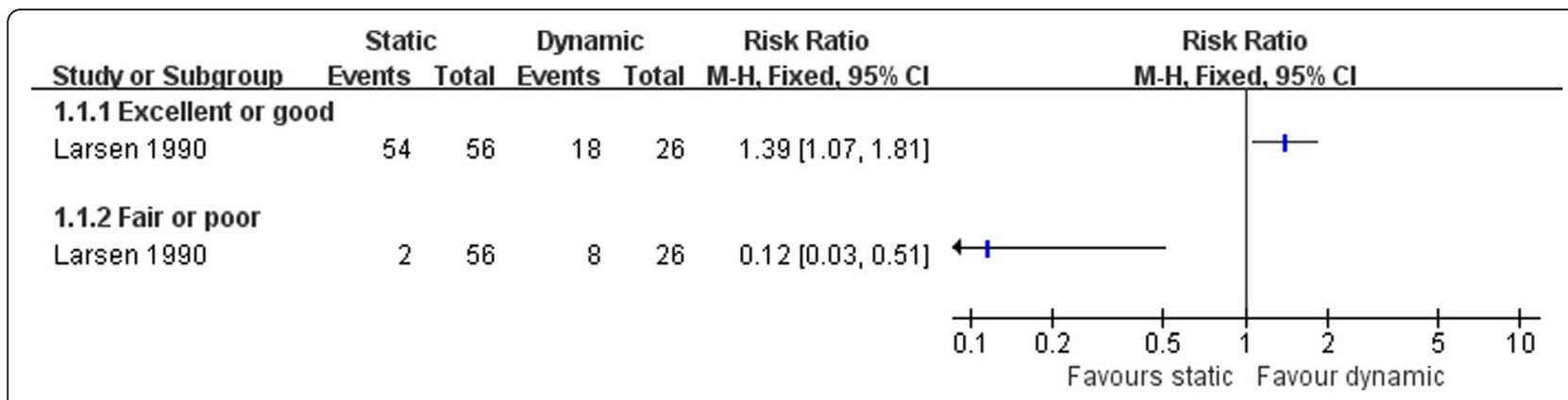

Fig. 4 Forest plot of comparison: 1 non-anatomic reconstruction (static tenodesis) versus non-anatomic reconstruction (dynamic tenodesis), outcome: 1.1 satisfaction at 25 months

ligament advanced reinforcement system (LARS). The main outcome measures of Porter et al. [68] were FAOS and complications.

We excluded a total of 26 studies. Detailed reasons for exclusion can be found in the characteristics of excluded studies (Additional file 9).

\section{Risk of bias in included studies}

See the "Risk of bias" tables in characteristics of included studies (Additional files 2, 3, 4, 5, 6, 7, and 8) and Figs. 2 and 3.

\section{Allocation (selection bias)}

Generation of the allocation sequence was considered of low risk of bias in six trials [63-68] and unclear risk in Rosenbaum et al. [69], the allocation of which was stratified randomized but no further details provided. Comparability of the groups was good and well described in three studies [64, 66, 69]. However, adequate random sequence generation together with adequate allocation concealment could not be confirmed in any of the trails. The other four studies provided no details of comparability.

\section{Blinding (performance bias and detection bias)}

In Larsen [67], it was well described that radiographic evaluation at the follow-up was blinded; none of the other studies provided information about blinding. We acknowledge blinding can be difficult in the comparison of ligament reconstruction and ligament repairment due to the additional operation incision in Evans/CS/LARS procedure, and thus, Hennrikus et al. [65], Porter et al. [68], and Rosenbaum et al. [69] were judged at being at high risk of both performance and detection bias.

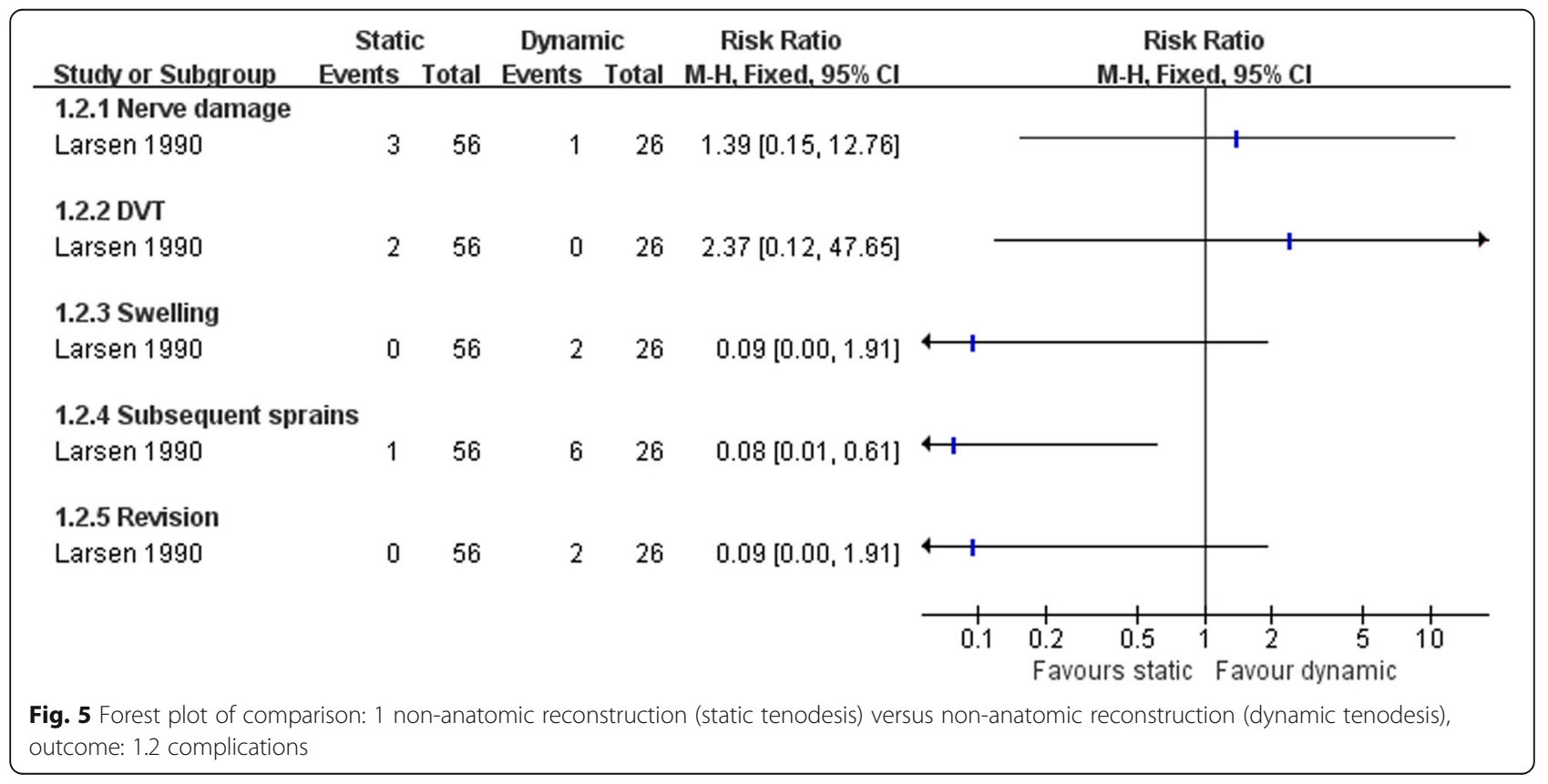




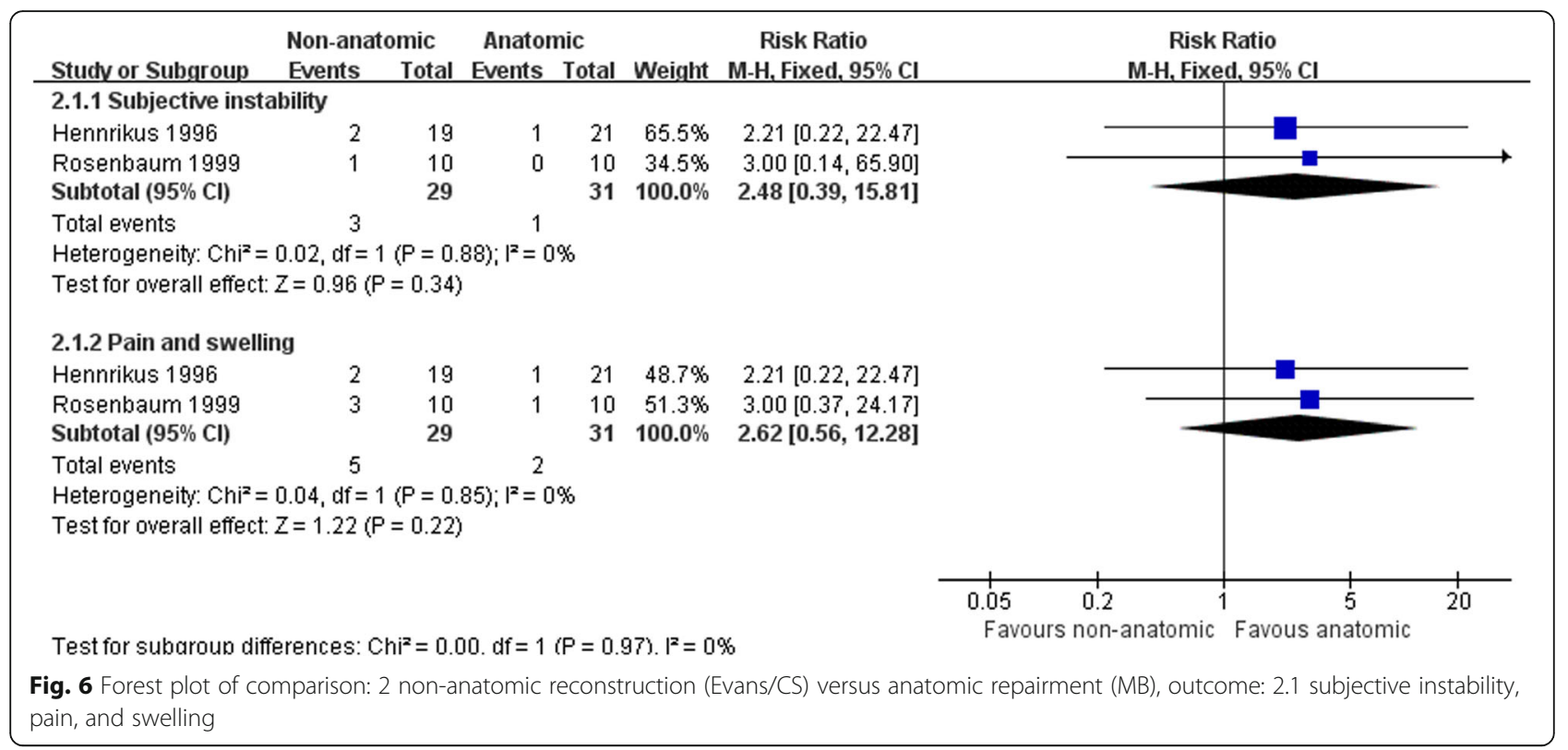

\section{Incomplete outcome data (attrition bias)}

In three studies $[66,68,69]$, there were no participants lost to follow-up. In Hennrikus et al. [65], it was unclear if there were participants lost to follow-up. In Larsen [67], prior to surgery, participants were randomized to one of the two treatment groups (static or dynamic tenodesis), but during the operation, 17 individuals in the dynamic repair group were excluded and not included in the analyses because the procedure was not feasible. In Cho et al. [63] and Cho et al. [64], it was assumed a 20\% withdrawal rate pre-operation and analyzed data when each group had enough eligible patients.

\section{Selective reporting (reporting bias)}

Three studies $[63,64,69]$ reported clearly specified outcome measures. We rated the other four studies [65-68] as at high risk of selective reporting bias due to lack of definition of the outcome measures collected in the methods section.

\section{Other potential sources of bias}

We rated all seven trials as at unclear risk of other bias due to lack of information to make judgments.

\section{Effects of interventions}

Non-anatomic reconstruction (static tenodesis) versus nonanatomic reconstruction (dynamic tenodesis)

Larsen [67] compared the clinical status after two kind of non-anatomic reconstruction procedures, the static and dynamic tenodesis. More patients were satisfied with the static tenodesis than dynamic procedure (Fig. 4). The dynamic tenodesis was associated with more subsequent sprains (Fig. 5). There was no strong evidence to show differences between the two groups in the numbers of participants with other complications (Fig. 5).

\section{Non-anatomic reconstruction versus anatomic repairment}

Hennrikus et al. [65] compared the CS procedure with a MB repairment, and Rosenbaum et al. [69] compared a modified Evans procedure with a MB repairment. There was no clear evidence to show differences between the two procedures in subjective instability $(3 / 29$ versus $1 / 31$; RR $2.48,95 \%$ CI 0.39 to 15.81 ) or pain and swelling at the follow-up (5/29 versus $2 / 31$; RR 2.62, 95\% CI 0.56 to 12.28 ) (Fig. 6). Hennrikus et al. [65] found a higher rate of nerve damage in the non-anatomic reconstruction $(11 / 20$ versus $2 / 20$; $R R$

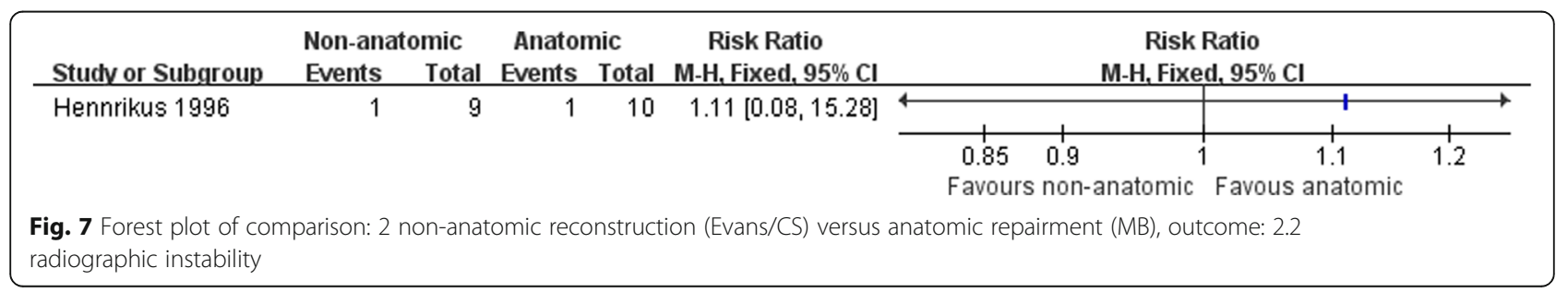




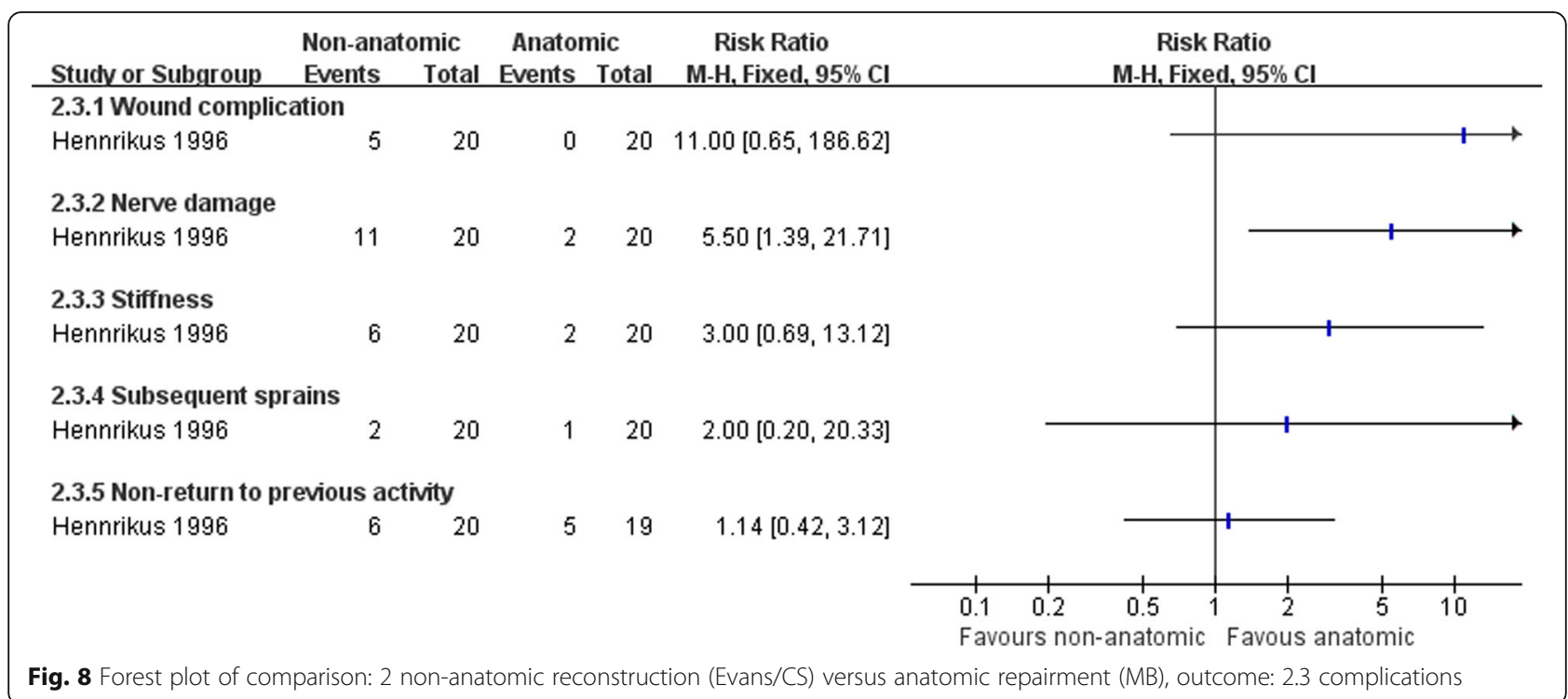

5.50, 95\% CI 1.39 to 21.71) (Fig. 8). There was no difference between the two procedures in the other complications and radiographic instability (Figs. 7 and 8). There was strong evidence that the non-anatomic reconstruction group have a greater reduction of the talar tilt angle (MD $-5.3^{\circ}, 95 \% \mathrm{CI}-9.71$ to -0.89 ) (Fig. 9). However, there was no clear evidence to show difference in reduction of anterior talar translation (MD - $0.70 \mathrm{~mm}, 95 \%$ CI -3.28 to 1.88$)$.

\section{Anatomic repairment (transosseous suture) versus anatomic repairment(imbrication)}

Both Karlsson et al. [66] and Cho et al. [63] compared transosseous suture and imbrication with inferior extensor retinaculum reinforcement. Karlsson et al. [66] reported that the mean operation time was significantly longer in the imbrication group (Fig. 10). In Cho et al. [63], the imbrication technique also used a single anchor to fix the ATFL and articular capsule. There was no statistically significant difference between the two operations in clinical satisfaction at more than 2 years of follow-up (Fig. 11). Similar findings of non-significant differences between the two groups applied to subjective instability, chronic pain, non-return to previous activity, anterior talar translation, talar tilt angle, and complications (Figs. 12, 13, 14, and 15).

\section{Anatomic repairment (single anchor, $M B$ ) versus anatomic repairment (double anchors, $M B$ )}

Cho et al. [64] compared the clinical outcomes of the MB procedure using single and double suture anchors for chronic lateral ankle instability. There was no statistically significant difference between the two operations in Karlsson score, clinical satisfaction, and postoperative complications (Figs. 16, 17, and 18). The talar tilt angle and anterior talar translation on stress radiographs using the Telos device had improved significantly in the two groups. The double anchor technique was superior with respect to the reduction in talar tilt angle (Fig. 19).

\section{Anatomic reconstruction (LARS) versus anatomic repairment (MB)}

Porter et al. [68] compared an anatomic reconstruction procedure (LARS) with a MB procedure. Forty-one patients took part in the study, 21 were randomized to the

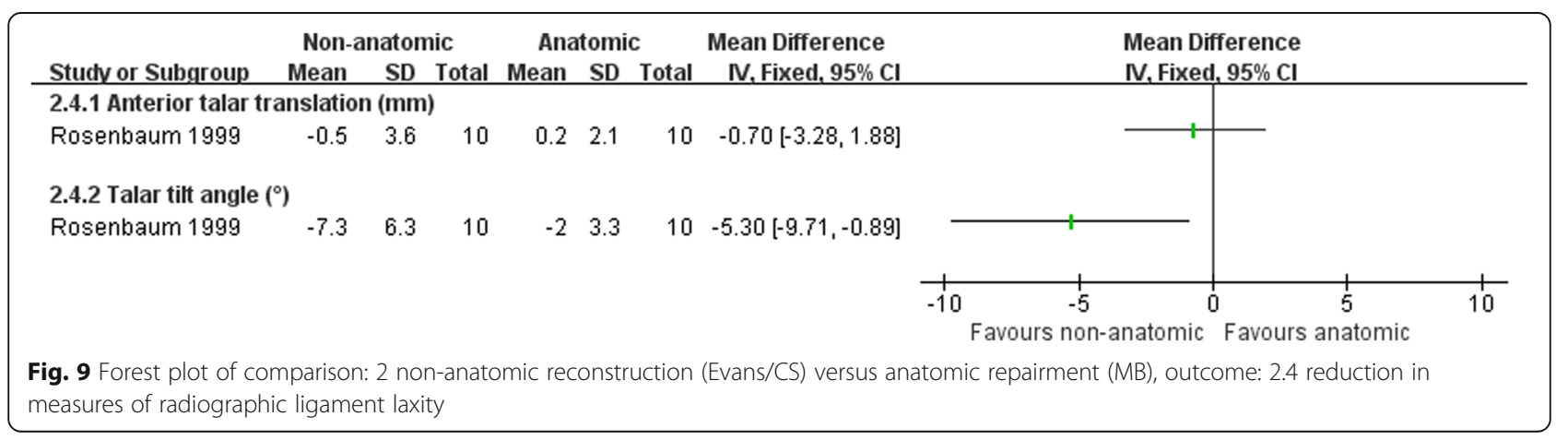




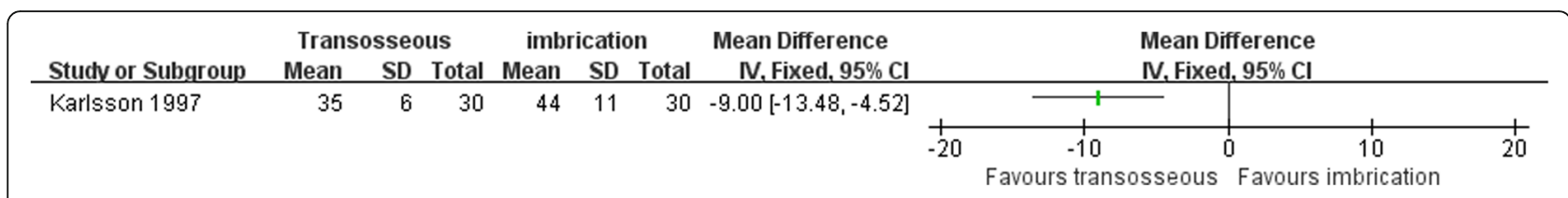

Fig. 10 Forest plot of comparison: 3 anatomic repairment (transosseous suture, MB) versus anatomic repairment (imbrication, MB), outcome: 3.1 operating time (minutes)

LARS group and 20 to the MB group. There was strong evidence that the LARS group had a better improvement in the total FAOS at both 1 year and 2 years post-surgery (Fig. 20), while there was no clear evidence to show difference between the two operations in postoperative complications (Fig. 21).

\section{Discussion}

To date, many surgical procedures have been applied to manage chronic ankle instability, a testament to the complexity of the current status. These procedures and their modifications fall into three categories: non-anatomic reconstruction, anatomic repairment, and anatomic reconstruction. Choosing a suitable surgical procedure is a complex question that has many arguments in the theory and clinical practice. This meta-analysis performed an extensive review of the literature systematically and compared different surgical techniques for management of chronic lateral ankle instability.

\section{Summary of main results}

The seven included studies fell in five clearly distinct groups comprising one study comparing different non-anatomic reconstruction procedures, three studies comparing different anatomic repairment techniques, two studies comparing non-anatomic reconstruction with anatomic repairment, and one study comparing anatomic reconstruction with anatomic repairment for CAI. There were only limited opportunities for pooling of data and few statistically significant differences in clinical outcomes between groups.

Larsen [67] comparing two different kinds of non-anatomic reconstruction procedures (dynamic and static tenodesis) found two outcomes favoring static tenodesis: better clinical satisfaction and fewer subsequent sprains.

Two studies $[65,69]$ have compared non-anatomic reconstruction versus anatomic repairment. In Hennrikus et al. [65], nerve injury was more frequent in non-anatomic reconstruction group. Rosenbaum et al. [69] reported that radiological measurement of ankle joint relaxation showed that non-anatomic reconstruction provided higher reduction of talar tilt angle.

Analysis of data from two researches [63, 66], comparing two anatomic repairment surgical procedures, showed no significant difference in any clinical outcome at follow-up, but Karlsson et al. [66] reported that the average operation time was significantly longer in the imbrication group.

One randomized study [64], comparing two different anatomic repairment techniques, found that the double anchor technique was superior with respect to the postoperative talar tilt than single anchor technique.

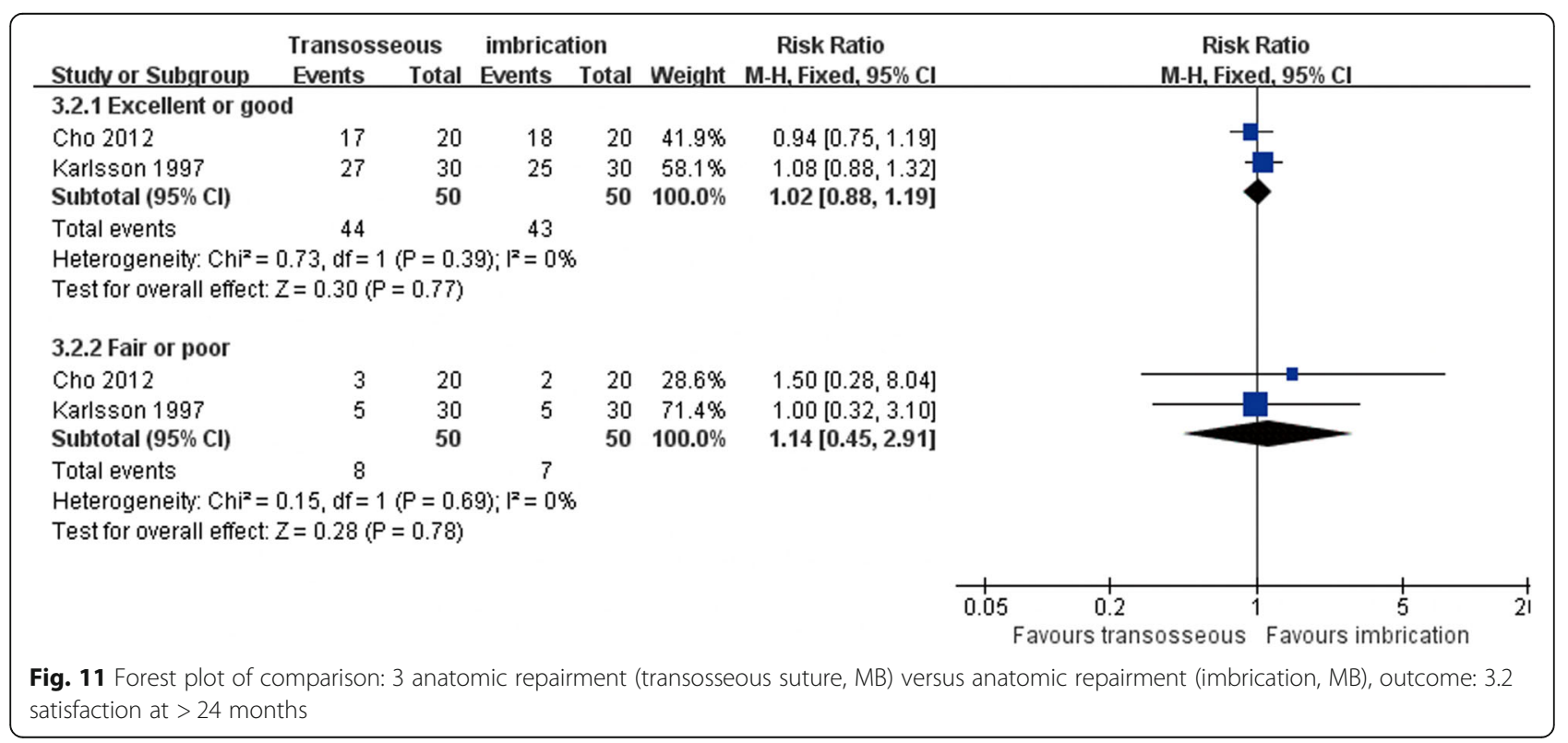




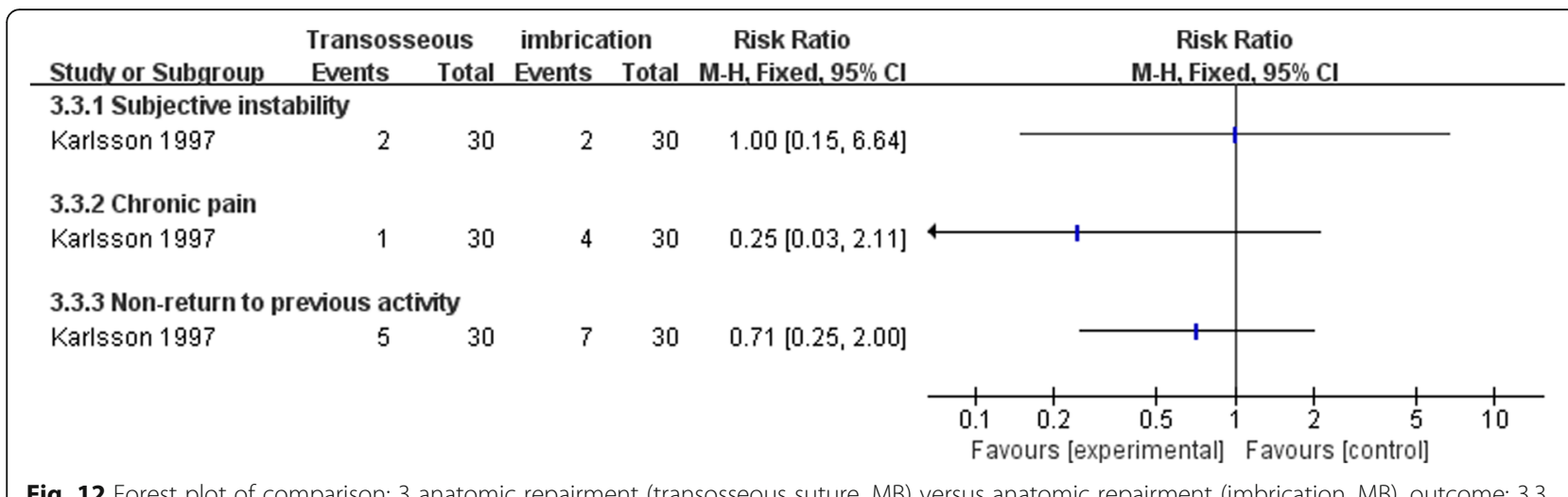

Fig. 12 Forest plot of comparison: 3 anatomic repairment (transosseous suture, MB) versus anatomic repairment (imbrication, MB), outcome: 3.3 subjective instability, pain, and activity

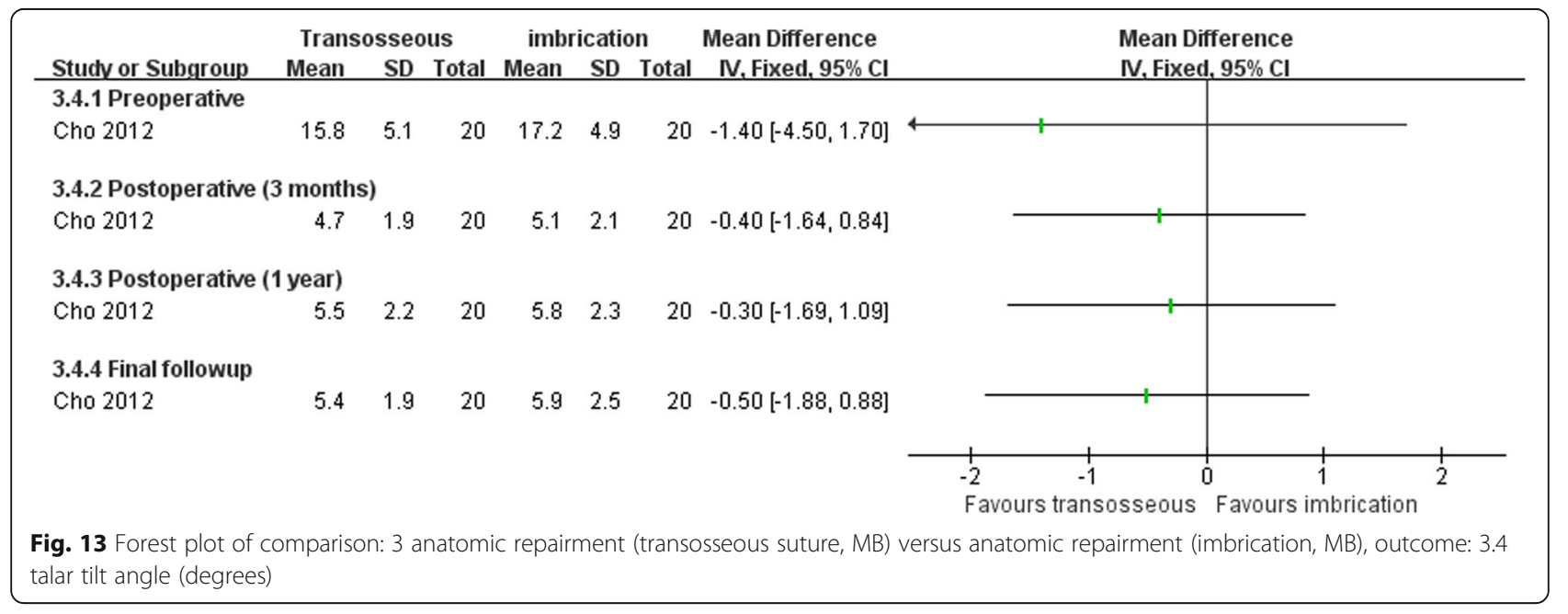

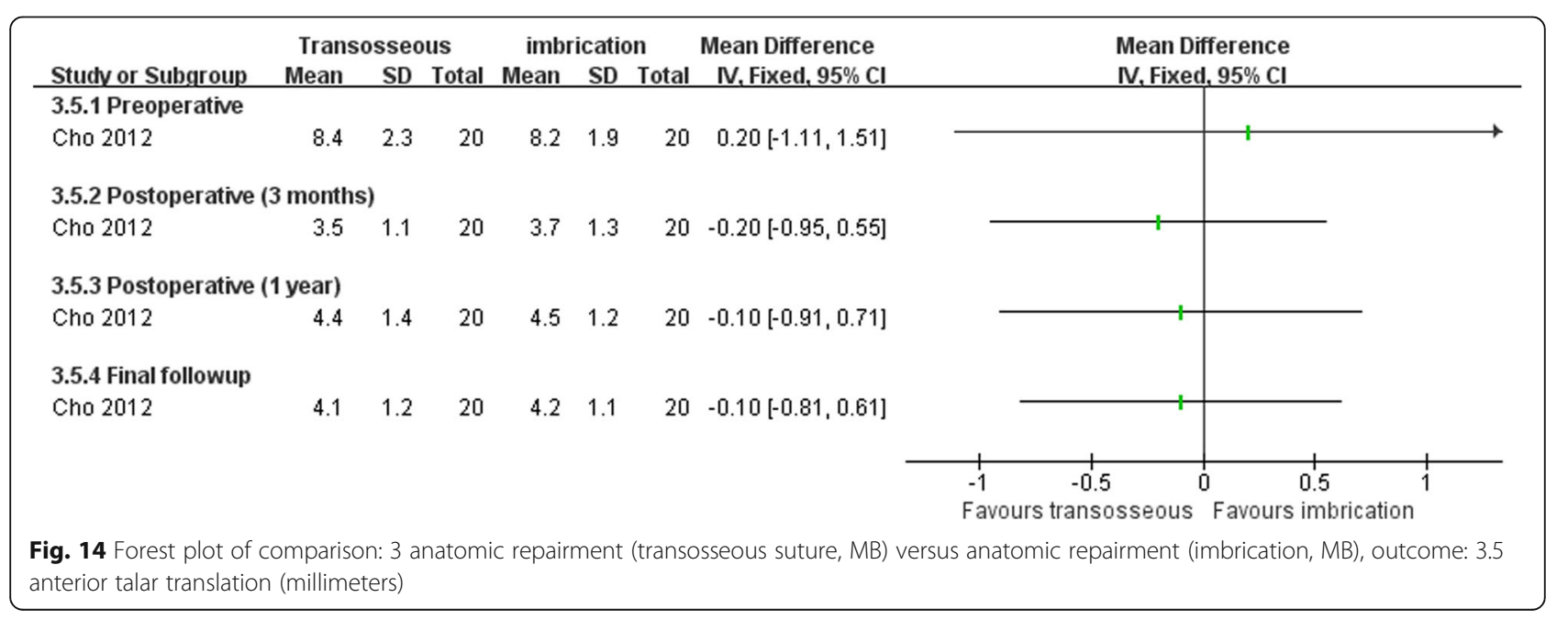




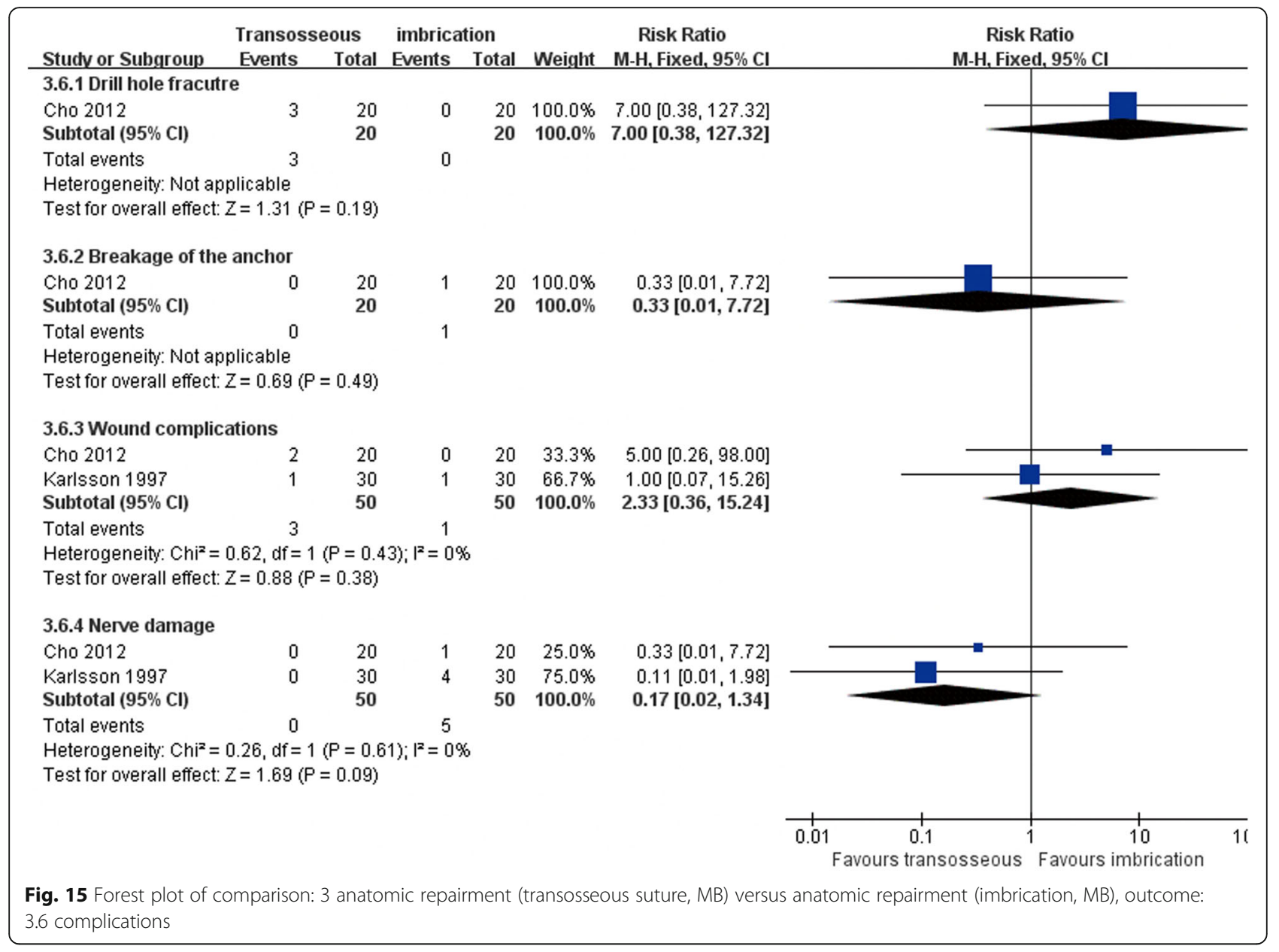

The other one study [68] compared an anatomic reconstruction procedure with a MB technique. Primary repair combined with LARS results in better patient-scored clinical outcome, at 2 years post-surgery, than the MB procedure.

\section{Overall completeness and applicability of evidence}

The search and selection criteria led to the inclusion of seven studies, which are somewhat heterogeneous. In all studies, interventions were described adequately, but the specific concrete operation steps of surgical protocols were different. In the section of non-anatomic reconstruction versus anatomic repairment, Hennrikus et al. [65] used CS procedure and Rosenbaum et al. [69] used a modified Evans procedure. In the section of transosseous suture anatomic repairment versus imbrication anatomic repairment, Cho et al. [63] used a single anchor to fix ATFL and articular capsule, while Karlsson et al. [66] did not. Inclusion criteria were adequately described in all studies. In three studies, the exclusion criteria were clearly described as well $[63,65,68]$. The other four

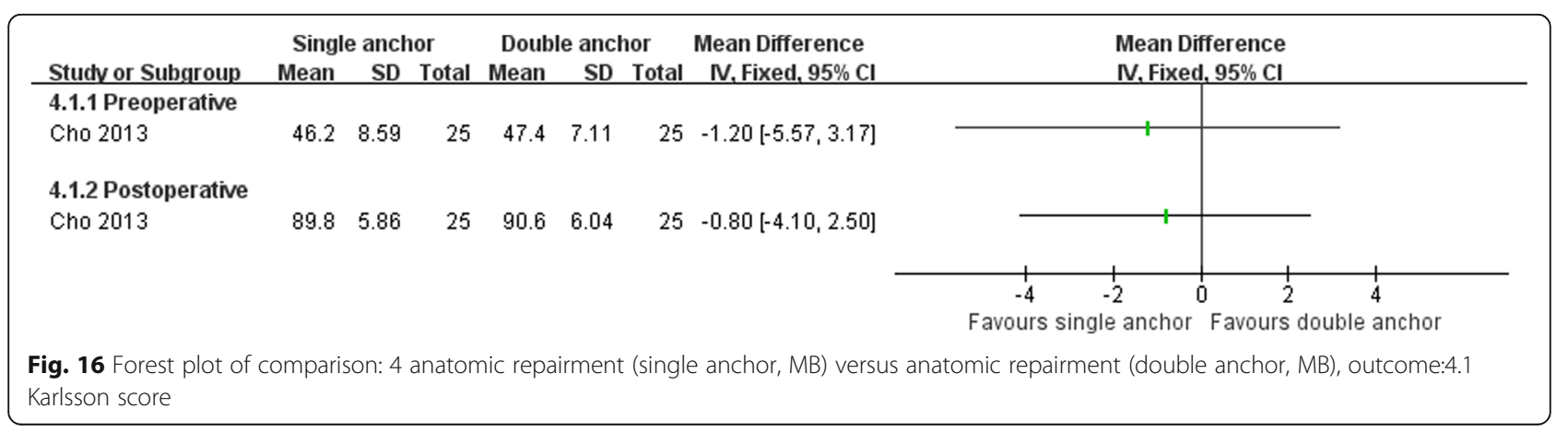




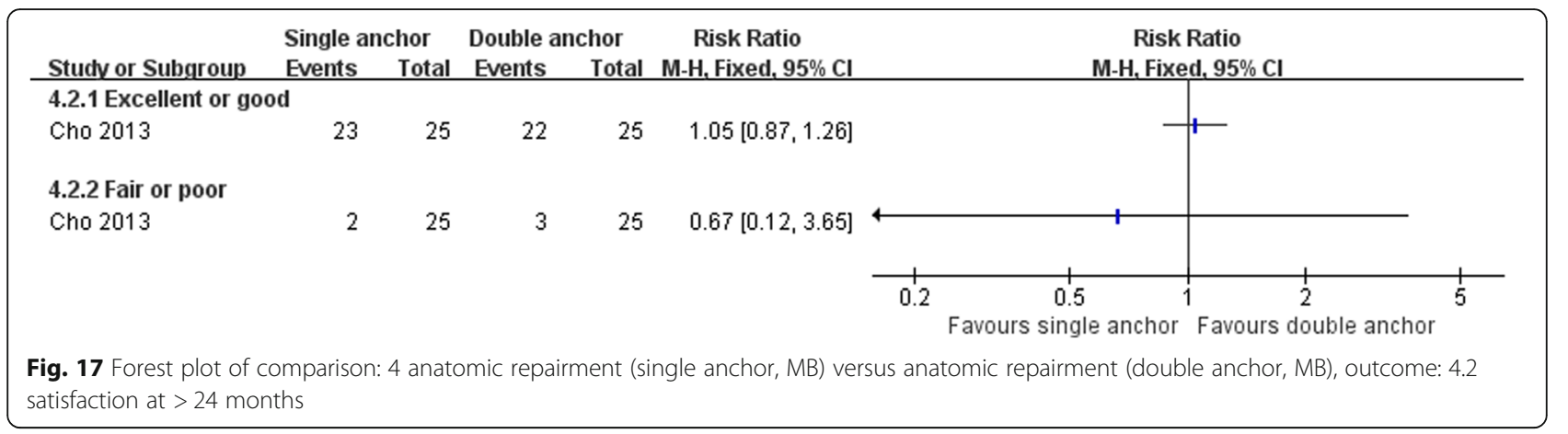

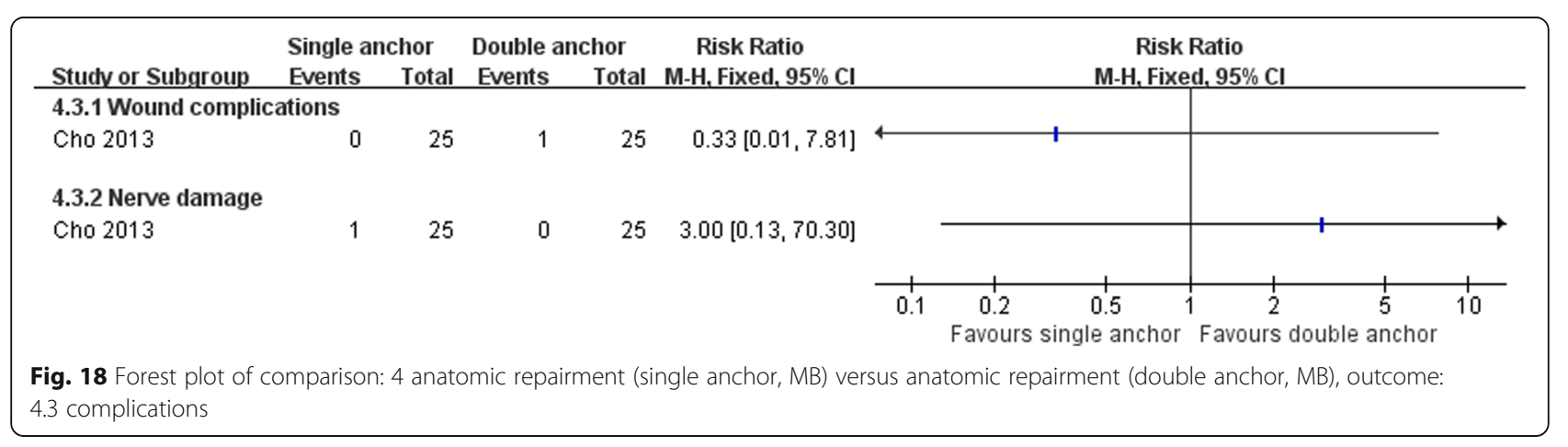

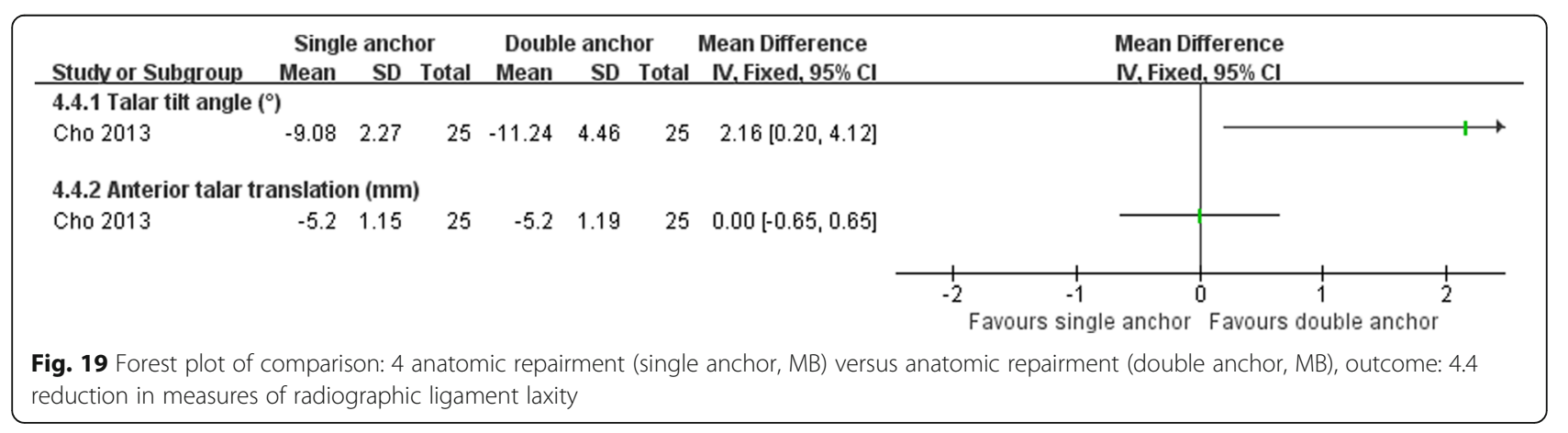

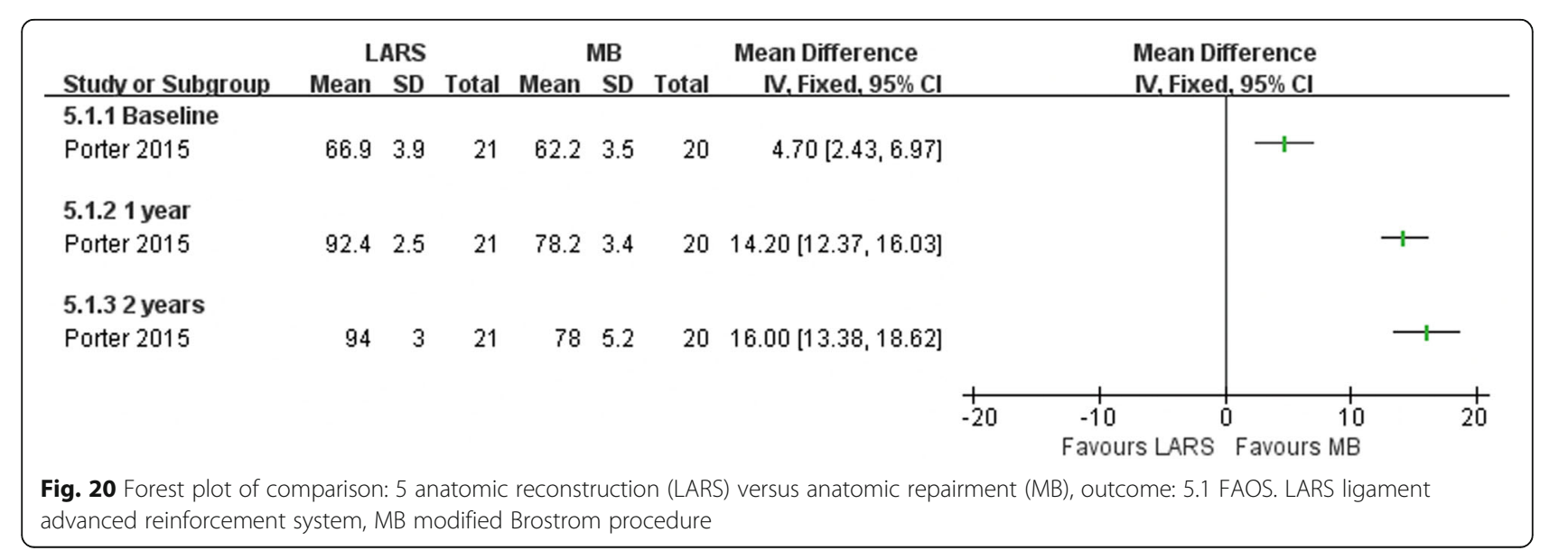




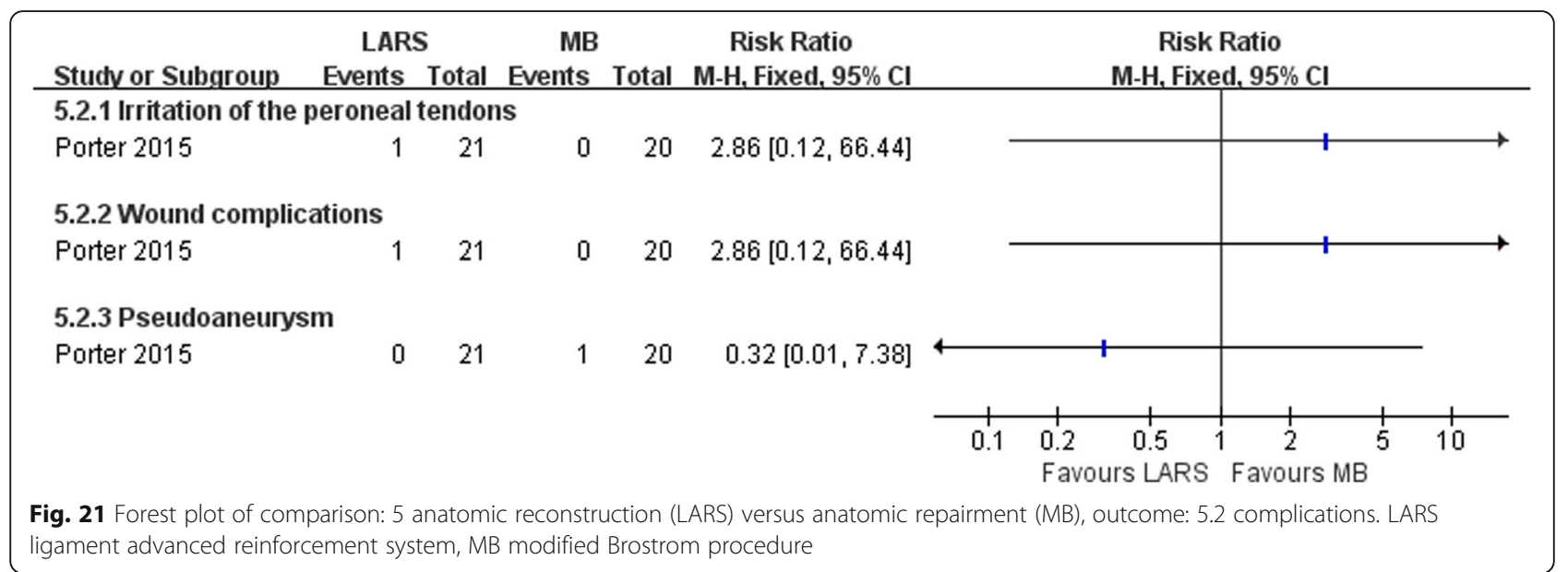

studies did not describe exclusion criteria or only mentioned a few criteria that did not exclude all conditions that could influence outcome.

\section{Quality of the evidence}

Limitations in the conduct, design, and reporting of the trials resulted in judgements of high risk or unclear of selection bias, attrition bias, detection bias, and reporting bias in one or more trials.

\section{Potential biases in the review process}

Although the search strategy was comprehensive and our methods of study selection were thorough, publication bias, study selection bias, and study identification bias can never completely be excluded.

\section{Agreements and disagreements with other studies or reviews}

Two systematic reviews evaluating surgical treatment techniques for CAI have been published [70, 71]. They included non-operative treatment and post-surgical rehabilitation studies as well. This review also includes three studies published after 2011.

\section{Conclusions}

Limited by the unclear to high risk of bias, few high-quality studies, and clinical heterogeneity, this review does not provide strong evidence on which to base practice. Based on the evidence, non-anatomic reconstruction abnormally increased inversion stiffness at the subtalar level as compare with anatomic repairment; this kind of procedure should be avoided to be the first-line surgical choice. Anatomic repairment procedure and anatomic reconstruction could acquire good clinical results; they are the appropriate first-line consideration for patients with chronic lateral ankle ligament laxity requiring surgical treatment. There is a need for high-quality randomized controlled trials evaluating the surgical treatment of chronic lateral ankle instability. Minimize bias and sufficient follow-up period are important for all trials.

\section{Additional files}

Additional file 1: Search strategies (DOCX $14 \mathrm{~kb}$ )

Additional file 2: Characteristics of included studies 1 (PDF $88 \mathrm{~kb}$ )

Additional file 3: Characteristics of included studies 2 (PDF $91 \mathrm{~kb}$ )

Additional file 4: Characteristics of included studies 3 (PDF $89 \mathrm{~kb}$ )

Additional file 5: Characteristics of included studies 4 (PDF $93 \mathrm{~kb}$ )

Additional file 6: Characteristics of included studies 5 (PDF $91 \mathrm{~kb}$ )

Additional file 7: Characteristics of included studies 6 (PDF $91 \mathrm{~kb}$ )

Additional file 8: Characteristics of included studies 7 (PDF $85 \mathrm{~kb}$ )

Additional file 9: Characteristics of excluded studies (PDF 90 kb)

\section{Abbreviations}

ATFL: Anterior talofibular ligament; CAl: Chronic ankle instability;

CFL: Calcaneofibular ligament; CS: Chrisman-Snook; FAOS: Foot and ankle outcome score; LARS: Ligament advanced reinforcement system;

MB: Modified Brostrom procedure; PTFL: Posterior talofibular ligament

Funding

This work was supported by the National Natural Science Foundation of China (No. 81772372)

Availability of data and materials

The datasets generated and analyzed during the current study are available in the PubMed repository, http://www.ncbi.nlm.nih.gov.

Authors' contributions

YXC designed, coordinated, and collected the data for the review. YH assisted with the data extraction and analysis. YX assisted with the study selection and quality assessment. $Y Z$ was involved as the third reviewer to solve

disagreement when necessary. $X Y X$ provided general advice and assisted with the writing of the review. All authors read and approved the final manuscript.

Ethics approval and consent to participate

Not applicable. All analyses were based on previous published studies; thus, no ethical approval and patient consent are required.

Consent for publication

Not applicable.

Competing interests

The authors declare that they have no competing interests. 


\section{Publisher's Note}

Springer Nature remains neutral with regard to jurisdictional claims in published maps and institutional affiliations.

Received: 9 April 2018 Accepted: 18 June 2018

Published online: 25 June 2018

\section{References}

1. Guillo S, Bauer T, Lee JW, Takao M, Kong SW, Stone JW, Mangone PG, Molloy A, Perera A, Pearce CJ, et al. Consensus in chronic ankle instability: aetiology, assessment, surgical indications and place for arthroscopy. Orthop Traumatol Surg Res. 2013;99:S411-9.

2. Ferran NA, Maffulli N. Epidemiology of sprains of the lateral ankle ligament complex. Foot Ankle Clin. 2006;11:659-62.

3. Hertel J. Functional anatomy, pathomechanics, and pathophysiology of lateral ankle instability. J Athl Train. 2002;37:364-75.

4. Peters JW, Trevino SG, Renstrom PA. Chronic lateral ankle instability. Foot Ankle. 1991;12:182-91.

5. Gerstner Garces JB. Chronic ankle instability. Foot Ankle Clin. 2012;17:389-98.

6. Chrisman OD, Snook GA. Reconstruction of lateral ligament tears of the ankle: an experimental study and clinical evaluation of seven patients treated by a new modification of the Elmslie procedure. J Bone Joint Surg Ser A. 1969;51:904-12.

7. Evans DL. Recurrent instability of the ankle; a method of surgical treatment. Proc R Soc Med. 1953;46:343-4.

8. Watson-Jones R. Recurrent forward dislocation of the ankle joint. J Bone Joint Surg B. 1952;34:519.

9. Gould N, Seligson D, Gassman J. Early and late repair of lateral ligament of the ankle. Foot Ankle. 1980;1:84-9.

10. Coughlin MJ, Schenck RC Jr, Grebing BR, Treme G. Comprehensive reconstruction of the lateral ankle for chronic instability using a free gracilis graft. Foot Ankle Int. 2004;25:231-41.

11. Boyer DS, Younger AS. Anatomic reconstruction of the lateral ligament complex of the ankle using a gracilis autograft. Foot Ankle Clin. 2006;11:585-95

12. Paterson R, Cohen B, Taylor D, Bourne A, Black J. Reconstruction of the lateral ligaments of the ankle using semi-tendinosis graft. Foot Ankle Int. 2000;21:413-9.

13. $X u X, H u$ M, Liu J, Zhu Y, Wang B. Minimally invasive reconstruction of the lateral ankle ligaments using semitendinosus autograft or tendon allograft. Foot Ankle Int. 2014;35:1015-21.

14. Hamilton WG, Thompson FM, Snow SW. The modified Brostrom procedure for lateral ankle instability. Foot Ankle. 1993;14:1-7.

15. Paden MH, Stone PA, McGarry JJ. Modified Brostrom lateral ankle stabilization utilizing an implantable anchoring system. J Foot Ankle Surg. 1994:33:617-22.

16. Angirasa AK, Barrett MJ. Talar anchor placement for modified Brostrom latera ankle stabilization procedure. J Am Podiatr Med Assoc. 2008:98:473-6.

17. Review Manager (RevMan). [Computer program]. Version 5.3. Copenhagen: The Nordic Cochrane Centre TCC; 2014

18. Higgins JP, Altman DG, Gotzsche PC, Juni P, Moher D, Oxman AD, Savovic J, Schulz KF, Weeks L, Sterne JA, et al. The Cochrane Collaboration's tool for assessing risk of bias in randomised trials. BMJ. 2011;343:d5928.

19. Best R, Bohle C, Schiffer T, Petersen W, Ellermann A, Brueggemann GP, Liebau C. Early functional outcome of two different orthotic concepts in ankle sprains: a randomized controlled trial. Arch Orthop Trauma Surg. 2015;135:993-1001.

20. Beynnon BD, Renstrom PA, Haugh L, Uh BS, Barker H. A prospective, randomized clinical investigation of the treatment of first-time ankle sprains. Am J Sports Med. 2006:34:1401-12.

21. Bleakley CM, O'Connor SR, Tully MA, Rocke LG, Macauley DC, Bradbury I, Keegan S, McDonough SM. Effect of accelerated rehabilitation on function after ankle sprain: randomised controlled trial. BMJ. 2010;340:C1964.

22. Cooke MW, Marsh JL, Clark M, Nakash R, Jarvis RM, Hutton JL, Szczepura A, Wilson S, Lamb SE: Treatment of severe ankle sprain: a pragmatic randomised controlled trial comparing the clinical effectiveness and costeffectiveness of three types of mechanical ankle support with tubular bandage. The CAST trial. Health Technol Assess 2009;13:iii, ix-x, 1-121.

23. de Bie RA, de Vet HC, Lenssen TF, van den Wildenberg FA, Kootstra G, Knipschild PG. Low-level laser therapy in ankle sprains: a randomized clinical trial. Arch Phys Med Rehabil. 1998;79:1415-20.

24. Hewitt DJ, Todd KH, Xiang J, Jordan DM, Rosenthal NR: Tramadol/acetaminophen or hydrocodone/acetaminophen for the treatment of ankle sprain: a randomized placebo-controlled trial. Ann Emerg Med 2007;49:468-480, 480 e461-462.
25. Kayali C, Agus $H$, Surer $L$, Turgut A. The efficacy of paracetamol in the treatment of ankle sprains in comparison with diclofenac sodium. Saudi Med J. 2007;28:1836-9.

26. Koll R, Buhr M, Dieter R, Pabst H, Predel HG, Petrowicz O, Giannetti B, Klingenburg S, Staiger C. Efficacy and tolerance of a comfrey root extract (Extr. Rad. Symphyti) in the treatment of ankle distorsions: results of a multicenter, randomized, placebo-controlled, double-blind study. Phytomedicine. 2004;11:470-7.

27. Lamb SE, Nakash RA, Withers EJ, Clark M, Marsh JL, Wilson S, Hutton JL, Szczepura A, Dale JR, Cooke MW. Clinical and cost effectiveness of mechanical support for severe ankle sprains: design of a randomised controlled trial in the emergency department [ISRCTN 37807450]. BMC Musculoskelet Disord. 2005;6:1

28. Mendel FC, Dolan MG, Fish DR, Marzo J, Wilding GE. Effect of high-voltage pulsed current on recovery after grades I and II lateral ankle sprains. J Sport Rehabil. 2010;19:399-410.

29. Moran M. An observer-blind comparison of diclofenac potassium, piroxicam and placebo in the treatment of ankle sprains. Curr Med Res Opin. 1990;12:268-74.

30. Moran M. Double-blind comparison of diclofenac potassium, ibuprofen and placebo in the treatment of ankle sprains. J Int Med Res. 1991:19:121-30.

31. Naeem M, Rahimnajjad MK, Rahimnajjad NA, Idrees Z, Shah GA, Abbas G. Assessment of functional treatment versus plaster of Paris in the treatment of grade 1 and 2 lateral ankle sprains. J Orthop Traumatol. 2015;16:41-6.

32. Sultan MJ, McKeown A, McLaughlin I, Kurdy N, McCollum CN. Elastic stockings or Tubigrip for ankle sprain: a randomised clinical trial. Injury. 2012;43:1079-83.

33. Thain PK, Bleakley CM, Mitchell AC. Muscle reaction time during a simulated lateral ankle sprain after wet-ice application or cold-water immersion. J Athl Train. 2015;50:697-703.

34. Tully MA, Bleakley CM, O'Connor SR, McDonough SM. Functional management of ankle sprains: what volume and intensity of walking is undertaken in the first week postinjury. Br J Sports Med. 2012;46:877-82.

35. Bahamonde LA, Saavedra H. Comparison of the analgesic and antiinflammatory effects of diclofenac potassium versus piroxicam versus placebo in ankle sprain patients. J Int Med Res. 1990;18:104-11.

36. Besch S, Dupré JP, Rodineau J, Dupuis JP, Saïdi K, Luciani JF, Bellacel K, Carpentier S, Banihachemi JJ. Lateral ankle sprain. Multicenter study of a new concept ankle orthosis: splint A2T. J Traumatol Sport. 2016;33:198-208.

37. Calandre EP, Ruiz-Morales M, Lopez-Gollonet JM, Hernandez MA, Guerrero JA, Rodenas E, Garcia-Sanz FL. Efficacy of oral streptokinase-streptodornase in the treatment of ankle sprains. Clin Orthop Relat Res. 1991;263:210-4.

38. Christakou A, Zervas $Y$, Lavallee $D$. The adjunctive role of imagery on the functional rehabilitation of a grade II ankle sprain. Hum Mov Sci. 2007;26:141-54.

39. Collado H, Coudreuse JM, Graziani F, Bensoussan L, Viton JM, Delarque A. Eccentric reinforcement of the ankle evertor muscles after lateral ankle sprain. Scand J Med Sci Sports. 2010;20:241-6.

40. Costantino C, Kwarecki J, Samokhin AV, Mautone G, Rovati S. Diclofenac epolamine plus heparin plaster versus diclofenac epolamine plaster in mild to moderate ankle sprain: a randomized, double-blind, parallel-group, placebocontrolled, multicentre, phase III trial. Clin Drug Investig. 2011;31:15-26.

41. Dalton JD Jr, Schweinle JE. Randomized controlled noninferiority trial to compare extended release acetaminophen and ibuprofen for the treatment of ankle sprains. Ann Emerg Med. 2006:48:615-23.

42. De Bie R. Functional treatment superior to cast immobilisation for complete ruptures of the lateral ligaments of the ankle. Aust J Physiother. 2003:49:143.

43. Diebschlag W, Nocker W, Bullingham R. A double-blind study of the efficacy of topical ketorolac tromethamine gel in the treatment of ankle sprain, in comparison to placebo and etofenamate. J Clin Pharmacol. 1990;30:82-9.

44. Dreiser RE, Charlot J, Lopez A, Ditisheim A. Clinical evaluation of niflumic acid gel in the treatment of uncomplicated ankle sprains. Curr Med Res Opin. 1990;12:93-9.

45. Dreiser RL, Riebenfeld D. A double-blind study of the efficacy of nimesulide in the treatment of ankle sprain in comparison with placebo. Drugs. 1993; 46(Suppl 1):183-6.

46. Fryer GA, Mudge JM, McLaughlin PA. The effect of talocrural joint manipulation on range of motion at the ankle. J Manip Physiol Ther. 2002;25:384-90.

47. Grindstaff TL, Beazell JR, Sauer LD, Magrum EM, Ingersoll CD, Hertel J. Immediate effects of a tibiofibular joint manipulation on lower extremity H-reflex measurements in individuals with chronic ankle instability. J Electromyogr Kinesiol. 2011;21:652-8.

48. Hale SA, Hertel J, Olmsted-Kramer LC. The effect of a 4-week comprehensive rehabilitation program on postural control and lower extremity function in individuals with chronic ankle instability. J Orthop Sports Phys Ther. 2007;37:303-11. 
49. Hamlyn C, Docherty CL, Klossner J. Orthotic intervention and postural stability in participants with functional ankle instability after an accommodation period. J Athl Train. 2012;47:130-5.

50. Hazanas Ruiz S, Galvez Alcaraz L, Cepas Soler JA. Functional stabilization versus orthopedic immobility in grade--II (mild) ankle sprain. Aten Primaria. 1999:23:425-8.

51. Kim KM, Ingersoll CD, Hertel J. Facilitation of Hoffmann reflexes of ankle muscles in prone but not standing positions by focal ankle-joint cooling. $J$ Sport Rehabil. 2015;24:130-9.

52. Konradsen L, Hølmer P, Søndergaard L. Early mobilizing treatment for grade III ankle ligament injuries. Foot Ankle. 1991;12:69-73.

53. Larsen E. Chronic lateral instability of the ankle. A radiographical, clinical and functional study with evaluation of synovial changes and predisposing foot deformities. Dan Med Bull. 1993;40:332-50.

54. Laufer Y, Rotem-Lehrer N, Ronen Z, Khayutin G, Rozenberg I. Effect of attention focus on acquisition and retention of postural control following ankle sprain. Arch Phys Med Rehabil. 2007:88:105-8.

55. Lopez-Rodriguez S, Fernandez de-Las-Penas C, Alburquerque-Sendin F, Rodriguez-Blanco C, Palomeque-del-Cerro L. Immediate effects of manipulation of the talocrural joint on stabilometry and baropodometry in patients with ankle sprain. J Manip Physiol Ther. 2007;30:186-92.

56. Lubbe D, Lakhani E, Brantingham JW, Parkin-Smith GF, Cassa TK, Globe GA, Korporaal C. Manipulative therapy and rehabilitation for recurrent ankle sprain with functional instability: a short-term, assessor-blind, parallel-group randomized trial. J Manip Physiol Ther. 2015;38:22-34.

57. Lyrtzis C, Natsis K, Papadopoulos C, Noussios G, Papathanasiou E. Efficacy of paracetamol versus diclofenac for Grade II ankle sprains. Foot Ankle Int. 2011;32:571-5.

58. Mazieres B, Rouanet S, Velicy J, Scarsi C, Reiner V. Topical ketoprofen patch $(100 \mathrm{mg})$ for the treatment of ankle sprain: a randomized, double-blind, placebo-controlled study. Am J Sports Med. 2005;33:515-23.

59. Myerson MS, Henderson MR. Clinical applications of a pneumatic intermittent impulse compression device after trauma and major surgery to the foot and ankle. Foot Ankle. 1993;14:198-203.

60. Pennington GM, Danley DL, Sumko MH, Bucknell A, Nelson JH. Pulsed, nonthermal, high-frequency electromagnetic energy (DIAPULSE) in the treatment of grade I and grade II ankle sprains. Mil Med. 1993;158:101-4.

61. Predel HG, Giannetti B, Koll R, Bulitta M, Staiger C. Efficacy of a comfrey root extract ointment in comparison to a diclofenac gel in the treatment of ankle distortions: results of an observer-blind, randomized, multicenter study. Phytomedicine. 2005;12:707-14.

62. van Rijn RM, van Heest JA, van der Wees $P$, Koes BW, Bierma-Zeinstra SM. Some benefit from physiotherapy intervention in the subgroup of patients with severe ankle sprain as determined by the ankle function score: a randomised trial. Aust J Physiother. 2009;55:107-13.

63. Cho BK, Kim YM, Kim DS, Choi ES, Shon HC, Park KJ. Comparison between suture anchor and transosseous suture for the modified-Brostrom procedure. Foot Ankle Int. 2012;33:462-8.

64. Cho BK, Kim YM, Kim DS, Choi ES, Shon HC, Park KJ. Outcomes of the modified Brostrom procedure using suture anchors for chronic lateral ankle instability - a prospective, randomized comparison between single and double suture anchors. J Foot Ankle Surg. 2013;52:9-15.

65. Hennrikus WL, Mapes RC, Lyons PM, Lapoint JM. Outcomes of the ChrismanSnook and modified-Brostrom procedures for chronic lateral ankle instability: a prospective, randomized comparison. Am J Sports Med. 1996;24:400-4.

66. Karlsson J, Eriksson BI, Bergsten T, Rudholm O, Swärd L. Comparison of two anatomic reconstructions for chronic lateral instability of the ankle joint. Am J Sports Med. 1997;25:48-53.

67. Larsen E. Static or dynamic repair of chronic lateral ankle instability. A prospective randomized study. Clin Orthop Relat Res. 1990;257:184-92

68. Porter M, Shadbolt B, Stuart R. Primary ankle ligament augmentation versus modified Brostrom-Gould procedure: a 2-year randomized controlled trial. ANZ J Surg. 2015;85:44-8.

69. Rosenbaum D, Engelhardt M, Becker HP, Claes L, Gerngross H. Clinical and functional outcome after anatomic and nonanatomic ankle ligament reconstruction: Evans tenodesis versus periosteal flap. Foot Ankle Int. 1999; 20:636-9.

70. de Vries JS, Krips R, Sierevelt IN, Blankevoort L. Interventions for treating chronic ankle instability. Cochrane Database Syst Rev. 2006;4:CD004124.

71. de Vries JS, Krips R, Sierevelt IN, Blankevoort L, van Dijk CN. Interventions for treating chronic ankle instability. Cochrane Database Syst Rev. 2011;8:CD004124.

\section{Ready to submit your research? Choose BMC and benefit from:}

- fast, convenient online submission

- thorough peer review by experienced researchers in your field

- rapid publication on acceptance

- support for research data, including large and complex data types

- gold Open Access which fosters wider collaboration and increased citations

- maximum visibility for your research: over $100 \mathrm{M}$ website views per year

At BMC, research is always in progress.

Learn more biomedcentral.com/submissions 